\title{
Autologous TAAs-loaded Autologous Dendritic Cells AV-GBM-1
}

National Cancer Institute

\section{Source}

National Cancer Institute. Autologous TAAs-loaded Autologous Dendritic Cells AV-GBM-

1. NCI Thesaurus. Code C154285.

A preparation of autologous dendritic cells (DCs) loaded with immunogenic tumorassociated antigens (TAAs) derived from cultured autologous g lioblastoma multiforme (GBM) tumor cells, with potential immunostimulatory and antineoplastic activities. Upon administration, the autologous TAA-loaded DCs AV-GBM-1 expose the immune system to the GBM neoantigens, which results in a cytotoxic T-lymphocyte (CTL)-mediated immune response against the autologous GBM cells leading to GBM cell lysis. 